\title{
OPTIMIZATION OF SHRINKAGE AND SURFACE-ROUGHNESS OF LTCC TAPE
}

\author{
Monika Dubey ${ }^{1}$, N Suri ${ }^{2}$, P K Khanna ${ }^{3}$ \\ ${ }^{1,2,3}$ CSIR - Central Electronics Engineering Research Institute, Pilani-333031, Rajasthan, India, \\ monikavi49@gmail.com
}

\begin{abstract}
The Low Temperature Co-fired Ceramics (LTCC) process is very popular in the electronics packaging industry and is broadly accepted for its low cost and rapid throughput. A multilayer LTCC 3-D structure generally shrinks during low temperature co-firing process. Shrinkage occurs in all three dimensions $X, Y$ and $Z$. Shrinkage has added a challenge to get high performance with low temperature co-fired ceramics designs and limited the yields of LTCC modules, components, subsystems and designs. Roughness is the measure of texture of surface of LTCC tape and a quantitative analysis of vertical deviation of real surface from its ideal form.
\end{abstract}

This paper describes variations in $X, Y$ and $Z$ directions of LTCC tape during firing at different temperatures and also describes about the surface roughness of LTCC tape. Data has been concentrated on the experimental results and observations.

Keywords-Low Temperature Co-fired Ceramics (LTCC), Shrinkage, Roughness, Green tape

\section{INTRODUCTION}

Low temperature co-fired ceramics (LTCC) materials are basically crystallisable glass or a mixture of glass and ceramics, (alumina, cordierite (Mg2A14Si5O18) or silica) [1]. The ceramic tapes of different properties are developed by using materials having different electrical and physical properties. The coefficient of thermal expansion can be adopted to match alumina, gallium arsenide or silicon [1]. There are a wide range of tape materials and processes available for LTCC modules. LTCC tapes are stacked, punched, laminated and co-fired up to temperature $\sim 850^{\circ} \mathrm{C}$ to form a dense unit structure. The binders of various composition and concentration are used to prepare LTCC green tape. They provide high mechanical strength to the composition of LTCC tape but due to some binders burn out problem arises in tape. Due to burn out problems after firing LTCC tape shrinks and roughness distribution changes. Surface roughness plays an important role in printing of pattern on LTCC tape. Shrinkage in LTCC tape affects the high performance of LTCC technology [2-6].

Shrinkage occurs in all three dimensions of LTCC tape of course uniformly and predictable and one can compensate for the shrinkage during the design. The flexural strength of an alumina formulation is $320 \mathrm{MPa}$, which render the fired structure extremely hard. The spongy of the LTCC system is lesser due to the use of vitreous material as alumina, glass binder [4]. For the substrate, shrinkage has measured along the compaction direction and the diametrical shrinkage from the geometry of the substrate. Repeatability and harmony of the shrinkage percentage must be the top criteria when designing the LTCC product because the shrinkage of LTCC substrate depends on the reactivity of the co-fired material containing ceramic oxide, alumina, glass, metals, organics and also the firing conditions such as temperature, time and ambient atmosphere [8].

\section{EXPERIMENTAL METHODOLOGY}

LTCC Du-Pont 951 tape consists of $45 \%$ glass-ceramic composite materials $40 \%$ alumina and $15 \%$ other organics, having low tolerance in di-electric constant (7.85) better thermal conductivity $(3 \mathrm{~W} / \mathrm{mK})$, high mechanical density (3.1g/cm3) and Young modulus (152GPa) [ 3].

Figure 1 show the process steps followed for developing LTCC substrate for optimization of shrinkage 


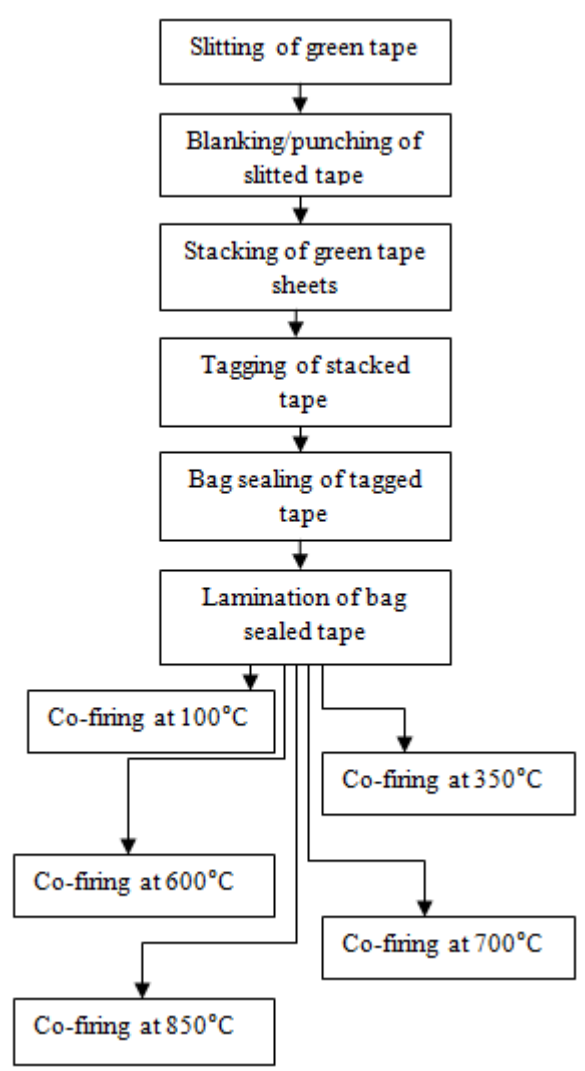

Figure 1: LTCC substrate preparation process flow

Slitting is the process in which big rolls of green tape are cut into the required size of $7.62 \mathrm{~cm} \times 7.62 \mathrm{~cm}$. Thickness of each slitted green tape is 10 mil. Blanking is cutting registration marks in to the substrate by a mechanical zig, so that tape can be handled easily for further processing. To provide thickness, LTCC tapes are collected together as stacking and tagging has been done by using the solder iron by transferring heat from one top layer to the subsequent lower layers to avoid misalignment. To do the lamination of the tapes it is necessary to tag and to seal bag. The stacked tapes are vacuum packaged in a poly urethane bag with pressure and heat of the DI water set to $3000 \mathrm{psi}$ and $70 \mathrm{oC}$ respectively is applied from all directions so that several individual green sheets are combined together to form one unit structure. After that a uniform heavy weight is used to make that uniform. Laminated ceramic tapes are co-fired in muffle furnace at different temperature as $100^{\circ} \mathrm{C}$, $350^{\circ} \mathrm{C}, 600^{\circ} \mathrm{C}, 700^{\circ} \mathrm{C}$ and $850^{\circ} \mathrm{C}$.

\section{RESULTS AND DISCUSSION}

Observations of LTCC tape have been taken to optimize shrinkage and roughness of LTCC substrates sintered at different temperature and 3-D view has been captured with the help of Zeta instruments optical profilers for 3D imaging and metrology [7].

\section{A. Shrinkage Optimization}

At $100^{\circ} \mathrm{C}$ volume and physical property of LTCC tape remain unchanged while at $100^{\circ} \mathrm{C}$ mechanical strength of single layer LTCC tape has increased.If a single layer LTCC green tape is placed in an oven for 50-60 minutes, and let allow the tape to settle for 24 hours, by this process the tape becomes rigid during the single-layer processing steps and this rigidity restricts tape movement (since stretching may cause misalignments and compromise shrinkage measurements at the surface) [6]. At $350^{\circ} \mathrm{C}$ volume of LTCC tape remain almost unchanged, and mechanical strength of LTCC tape has become low and it is fragile,the surface color of LTCC tape becomes light blue. Binders and plasticizers are used to provide high mechanical strength to LTCC tape, at $350^{\circ} \mathrm{C}$ binders and plasticizers are evaporated so LTCC tape becomes brittle and surface has been rough.

At higher temperature $600^{\circ} \mathrm{C}$, there is a weight loss of $8-10 \%$ tape becomes brittle for low intensity with low mechanical strength. After $650^{\circ} \mathrm{C}$ LTCC tape starts to densify and then liquid glass is formed. Near to this temperature the particles of Alumina start to dissolve and the amount of glassy phase increases up to $700{ }^{\circ} \mathrm{C}$. From $650{ }^{\circ} \mathrm{C}$ to $700{ }^{\circ} \mathrm{C}$ the sintering of the LTCC takes place and the material is fully sintered at $700^{\circ} \mathrm{C}$. At $700^{\circ} \mathrm{C}, \mathrm{LTCC}$ substrate shrinks as much as final shrinkage and becomes tough weight loss is also as much as final weight loss but the surface color is not deep blue, it is almost equal to green tape. At $850^{\circ} \mathrm{C}$ shrinkage occurs at LTCC tape about $12 \pm 0.8 \%$ in $\mathrm{X}-\mathrm{Y}$ direction and $15 \pm 0.8 \%$ in $\mathrm{Z}$ direction having high intensity. LTCC tape becomes hard and tough. The surface color of completely fired LTCC tape is deep blue and weight loss is about $11 \pm 0.8 \%$. Shrinkage rate of LTCC tape according to different sintering temperature has shown in table 1.

TABLE 1 SHRINKAGE RATE OF LTCC TAPE ACCORDING TO DIFFERENT SINTERING TEMPERATURE

\begin{tabular}{|l|l|l|l|l|}
\hline $\begin{array}{l}\text { S. } \\
\text { No }\end{array}$ & $\begin{array}{l}\text { Sintering } \\
\text { at }{ }^{\circ} \mathrm{C}\end{array}$ & $\begin{array}{l}\text { Size }(\mathrm{X}, \mathrm{Y}, \\
\mathrm{Z})\end{array}$ & $\begin{array}{l}\text { Weight } \\
(\mathrm{gm} .)\end{array}$ & Remark \\
\hline 1 & 100 & $\begin{array}{l}7.62 \mathrm{~cm}, \\
7.62 \mathrm{~cm}, \\
0.702 \mathrm{~mm}\end{array}$ & 9.60 & No change \\
& & $\begin{array}{l}7.62 \mathrm{~cm}, \\
7.62 \mathrm{~cm}, \\
0.702 \mathrm{~mm}\end{array}$ & 9.60 & $\begin{array}{l}\text { Low } \\
\text { mechanical } \\
\text { strength,fragil } \\
\text { e }\end{array}$ \\
\hline 2 & 350 & $\begin{array}{l}7.62 \mathrm{~cm}, \\
7.62 \mathrm{~cm}, \\
0.702 \mathrm{~mm}\end{array}$ & 8.54 & $\begin{array}{l}\text { Low } \\
\text { mechanical } \\
\text { strength,fragil } \\
\text { e }\end{array}$ \\
\hline 3 & 600 & & & \\
\hline
\end{tabular}




\begin{tabular}{|c|c|c|c|c|}
\hline 4 & 700 & $\begin{array}{l}6.76 \mathrm{~cm}, \\
6.76 \mathrm{~cm}, \\
0.596 \mathrm{~mm}\end{array}$ & 8.46 & $\begin{array}{l}\text { Shrinks and } \\
\text { tough }\end{array}$ \\
\hline 5 & 850 & $\begin{array}{l}6.76 \mathrm{~cm}, \\
6.76 \mathrm{~cm}, \\
0.596 \mathrm{~mm}\end{array}$ & 8.46 & $\begin{array}{l}\text { Shrinks and } \\
\text { hard, } \\
\text { Deep blue } \\
\text { surface color }\end{array}$ \\
\hline
\end{tabular}

\section{B. Roughness optimization}

Roughness (measure of texture of surface) of LTCC tape sintered at different temperature has measured with Zeta Instrument [7] shown in table 2. Surface roughness of green tape has been viewed non-uniformly at different edges and centre. After lamination LTCC tape became a monolithic uniform structure but roughness of structure is different at different points but greater than green tape although volume and property of tape remains unchanged.

TABLE 2 ROUGHNESS OF LTCC TAPE ACCORDING TO DIFFERENT SINTERING TEMPERATURE

\begin{tabular}{|l|l|l|l|}
\hline $\begin{array}{l}\text { S } \\
\text { No }\end{array}$ & $\begin{array}{l}\text { Sintering } \\
\text { At }\left({ }^{\circ} \mathrm{C}\right)\end{array}$ & $\begin{array}{l}\text { Average } \\
\text { Surface } \\
\text { Roughness } \\
(\mathrm{Sa})(\mu \mathrm{m})\end{array}$ & $\begin{array}{l}\text { Skewness } \\
(\text { asymmetry of } \\
\text { distribution })(\text { Ssk }) \\
(\mu \mathrm{m})\end{array}$ \\
\hline 1 & Green Tape & 0.8597 & -0.0072 \\
\hline 2 & Laminated & 1.495 & -0.0129 \\
\hline 3 & 100 & 1.045 & -0.0180 \\
\hline 4 & 350 & 1.131 & -0.0237 \\
\hline 5 & 600 & 0.5922 & -0.0088 \\
\hline 6 & 700 & 0.4162 & -0.0082 \\
\hline 7 & 850 & 0.3154 & -0.0157 \\
\hline
\end{tabular}

At $100^{\circ} \mathrm{C}$ volume and physical property of LTCC tape remains unchanged but roughness of surface is not unifomly distributed. Fragile tape sintered at $350^{\circ} \mathrm{C}$ and $600^{\circ} \mathrm{C}$ have various roughness value at different points. But roughness value for LTCC tape fired at $700^{\circ} \mathrm{C}$ and $850^{\circ} \mathrm{C}$ is almost same at different points.

\section{CONCLUSIONS}

LTCC substrate has been sintered at different temperature. Shrinkage take place at $700^{\circ} \mathrm{C}$ and before this temperature LTCC substrate becomes fragile and roughness of LTCC substrates which sintered at different temperature is not uniform but it decreases as temperature increases as shown in figure 2. But roughness of tape fired at $700^{\circ} \mathrm{C}$ and $850^{\circ} \mathrm{C}$ is almost uniform as shown in figure 3 and figure 4. Rough surfaces usually wear more quickly and have higher friction coefficients, so for better printing of pattern on LTCC tape roughness is necessary since it promotes adhesion.

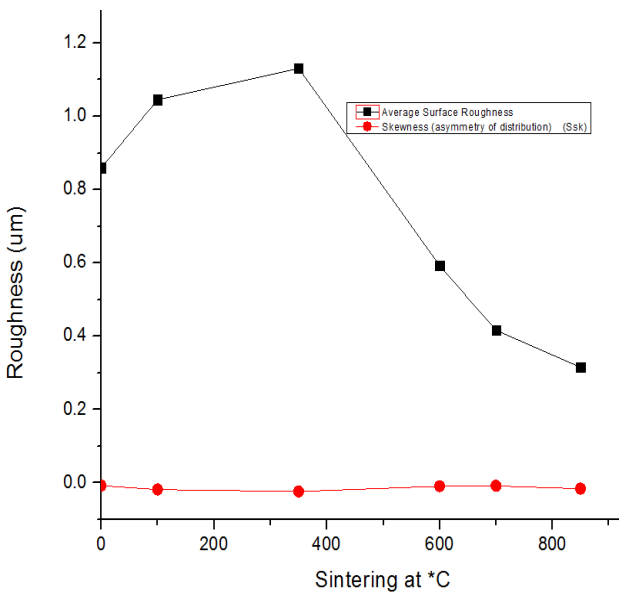

Figure 2: Graph between Different roughness parameters and sintering temperature

Data may be important for well defined cavity manufacturing and integration of passive components with LTCC substrate.

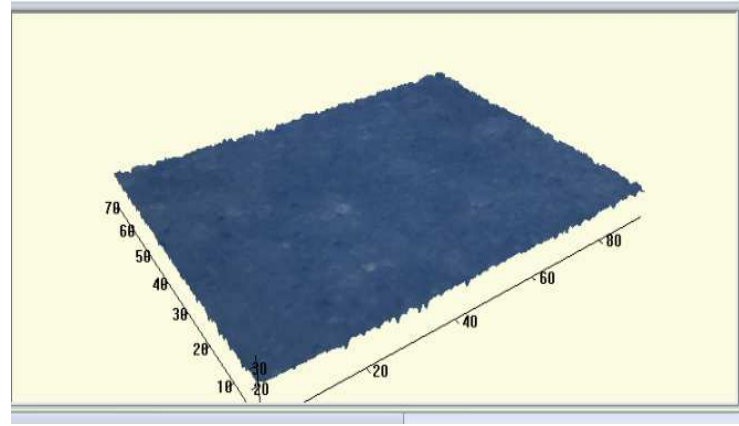

Figure 3: 3-D view of LTCC substrate fired at $700^{\circ} \mathrm{C}$

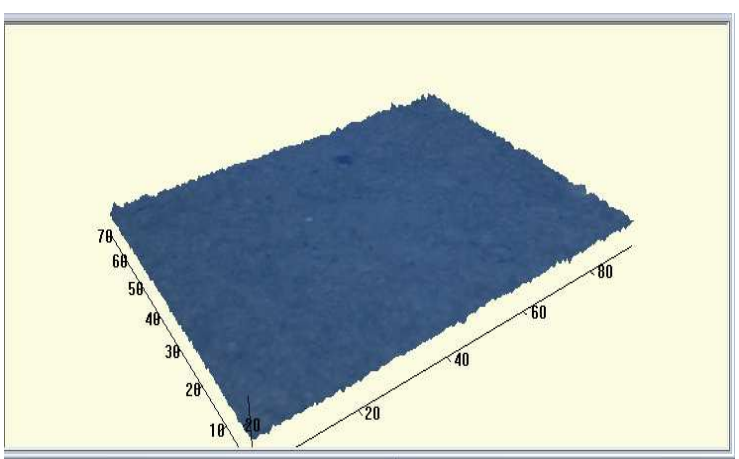

Figure 4: 3-D view of LTCC substrate fired at $850^{\circ} \mathrm{C}$

\section{ACKNOWLEDGMENTS}

The authors are highly thankful to director of CSIR-Central Electronics Engineering Research Institute Pilani (Rajasthan) India to provide lab facilities. 


\section{REFERENCES}

[1] Golonka, L. J. "Technology and applications of low temperature cofired ceramic (LTCC) based sensors and microsystems." Bull Polish Acad Sci Tech Sci 54.2 (2006).

[2] Wahlers, R. L., A. H. Feingold, and M. Heinz, "Lead free, zero shrink, substrate bonded LTCC system." Proceedings-Spie The International Society For Optical Engineering, International Society For Optical Engineering; 1999, 2003.

[3] Birol, Hansu. "Fabrication of low temperature co-fired ceramic (LTCC)-based sensor and micro-fluidic structures." PhD, EPFL, Switzerland (2007).

[4] Park, Jung-Juu, et al. "The development of a fully integrated micro-channel fuel processor using low temperature co-fired ceramic (LTCC)." Journal of Industrial and Engineering Chemistry 15.5 (2009): 618-623.

[5] Gongora-Rubio, Mario Ricardo, et al. "Overview of low temperature co-fired ceramics tape technology for meso-system technology (MsST)." Sensors and Actuators A: Physical 89.3 (2001): 222-241.

[6] Girardi, Michael, et al. "Response predicting LTCC firing shrinkage: A response surface analysis study." Journal of microelectronics and electronic packaging 6.2 (2009): 114-118. [7] http://www.zeta-inst.com/page/led-app

[8] Rosidah Alias "The Effects of Sintering Temperature Variations on Microstructure Changes of LTCC Substrate" Sintering of Ceramics - New Emerging Techniques (2012) ISBN 978-953-51-0017-1:60-84 